\title{
Soil surface roughness: comparing old and new measuring methods and application in a soil erosion model
}

\author{
L. M. Thomsen ${ }^{1}$, J. E. M. Baartman ${ }^{1}$, R. J. Barneveld ${ }^{2}$, T. Starkloff ${ }^{2}$, and J. Stolte ${ }^{2}$ \\ ${ }^{1}$ Soil Physics and Land Management Group, Wageningen University, Wageningen, the Netherlands \\ ${ }^{2}$ Norwegian Institute for Agricultural and Environmental Research, Bioforsk, Ås, Norway \\ Correspondence to: L. M. Thomsen (linemajthomsen@gmail.com)
}

Received: 10 October 2014 - Published in SOIL Discuss.: 27 November 2014

Revised: 8 March 2015 - Accepted: 27 March 2015 - Published: 24 April 2015

\begin{abstract}
Quantification of soil roughness, i.e. the irregularities of the soil surface due to soil texture, aggregates, rock fragments and land management, is important as it affects surface storage, infiltration, overland flow, and ultimately sediment detachment and erosion. Roughness has been measured in the field using both contact methods (such as roller chain and pinboard) and sensor methods (such as stereophotogrammetry and terrestrial laser scanning (TLS)). A novel depth-sensing technique, originating in the gaming industry, has recently become available for earth sciences: the Xtion Pro method. Roughness data obtained using various methods are assumed to be similar; this assumption is tested in this study by comparing five different methods to measure roughness in the field on $1 \mathrm{~m}^{2}$ agricultural plots with different management (ploughing, harrowing, forest and direct seeding on stubble) in southern Norway. Subsequently, the values were used as input for the LISEM soil erosion model to test their effect on the simulated hydrograph at catchment scale. Results show that statistically significant differences between the methods were obtained only for the fields with direct seeding on stubble; for the other land management types the methods were in agreement. The spatial resolution of the contact methods was much lower than for the sensor methods (10000 versus at least 57000 points per square metre). In terms of costs and ease of use in the field, the Xtion Pro method is promising. Results from the LISEM model indicate that especially the roller chain overestimated the random roughness (RR) values and the model subsequently calculated less surface runoff than measured. In conclusion, the choice of measurement method for roughness data matters and depends on the required accuracy, resolution, mobility in the field and available budget. It is recommended to use only one method within one study.
\end{abstract}

\section{Introduction}

Soil surface roughness is defined as the irregularities of the soil surface, caused by factors such as soil texture, aggregate size, rock fragments, vegetation cover and land management. Soil roughness affects surface storage, infiltration, overland flow, and ultimately sediment detachment and erosion (Amoah et al., 2013). As soil roughness is usually too small to be captured by conventional topographic mapping or digital elevation models, it is also referred to as soil microtopography and can be subdivided into four different categories (Takken, 2000): (i) micro-relief variations or grain roughness, mainly determined by the soil type; (ii) random roughness, related to soil aggregates; (iii) oriented roughness, describing the systematic variations in topography due to, for example, tillage; and (iv) higher-order roughness representing elevation variations in the field, such as embankments or field borders. In this study, we focus on the second type: random roughness.

Since the late 1950s (Zobeck and Onstad, 1987), soil surface roughness has been quantified using various indices, mostly based on statistical indicators of surface elevation point measurements (Doren and Van Linden, 1986; Lehrsch et al., 1988). One of the most commonly used soil 
roughness indices is random roughness, defined by Allmaras et al. (1966) as the natural logarithm of the standard deviation of multiple height measurements after removing the effects of slope and oriented roughness and the $10 \%$ upper and lower extreme values. Cremers et al. (1996) showed that the standard deviation of height measurements after removing slope effects could be used equally well. This latter definition of random roughness (RR) is used in this study.

The RR index was found to vary significantly with changes in land use and tillage orientation as well as over time (Cremers et al., 1996). The index is used in several equations to estimate surface depression storage, i.e. the fraction of surface covered with water and amount of excess rainfall needed before runoff starts, for instance in physically based hydrological or soil erosion models. In such models, roughness is either included explicitly by performing hydraulic calculations at high spatio-temporal resolutions (Esteves et al., 2000; Fiedler and Ramirez, 2000), but more commonly by using a roughness parameter as a proxy value in the runoff process in the simulation. Arguably, one of the reasons that erosion modelling is still not satisfactory (e.g. Takken et al., 1999; De Vente et al., 2013) is the lack of input data that capture the heterogeneity of the area of interest (Kværnø, 2011; Sheikh et al., 2010). Therefore, one way to improve erosion model performance is to improve the accuracy and precision of the model input data such as random roughness, using new sensor measurement methods, and to test how sensitive the model is to variations in input data.

Soil roughness has been measured in the field using various methods (García Moreno et al., 2010), some of which capture a profile or transect of elevation data, while others cover an area, typically extending a few square metres. These methods differ in obtainable accuracy and resolution, as well as in practical aspects, such as costs and workability in the field. Jester and Klik (2005) compared measured roughness data from pin profilers and a roller chain as contact methods and from laser scanner and stereophotogrammetry as sensor methods. They did not compare between the contact and noncontact methods and did not consider a specific purpose for which the resulting roughness data would be used.

The current study extends the study by Jester and Klik (2005) by directly comparing roughness values measured using five different methods on different agricultural surfaces. The measurement methods evaluated were the contact methods pinboard and roller chain and the sensor methods terrestrial laser scanner (TLS), stereophotogrammetry and the new Xtion Pro method (ASUS, 2013). This latter depthsensing technology originates in the gaming industry and has recently been used in earth science studies (Mankoff and Russo, 2012). For example, Hammerle et al. (2014) used it to model a karst cave, Tortini et al. (2014) used it to assess volcano deformation and Brouwer (2013) used it to assess tree metrics. The advantage over state-of-the-art terrestrial laser scanners is the increased mobility, especially relevant for erosion monitoring at the landscape scale, and the relatively low costs (James and Quinton, 2014; Mankoff and Russo, 2012). Next to direct comparison of the measured roughness values from the five methods, they were also compared in terms of their effect on the output of the distributed, process-based soil erosion model LISEM (Limburg Soil Erosion Model; De Roo et al., 1996a). The main objective of the study was to obtain a quantitative comparison of the different measurement methods. Subsequently, the effects of the differences on the output of a soil erosion model were tested.

\section{Methodology}

\subsection{Study area}

This study was conducted in the Skuterud catchment $\left(4.5 \mathrm{~km}^{2}\right)$, located east of Ås, approximately $30 \mathrm{~km}$ south of Oslo, Norway $\left(59.67^{\circ} \mathrm{N}, 10.83^{\circ} \mathrm{E}\right.$; Fig. 1). The landscape is undulating with elevations ranging from 92 to $150 \mathrm{~m}$ a.s.l. Slopes are mainly between 2 and $10 \%$, with the steepest slopes in the eastern and western part of the catchment. Annual average temperature is $5.3^{\circ} \mathrm{C}$ and annual average precipitation is $785 \mathrm{~mm}$. Sixty percent of the catchment area is cultivated land, while about $30 \%$ is forest, mainly coniferous or mixed coniferous-deciduous; $7 \%$ is urban settlement and roads; and $2 \%$ is covered by forested peatland located in the southernmost depression in the catchment. Geologically, the area mainly consists of marine deposits. Coarse marine shore deposits dominate on the fringe of the cultivated areas and in the forest. The dominant soil types in the central part are marine silt loam and silty clay loam soils (Albeluvisols and Stagnosols). In the areas with shore deposits, sandy and loamy sand soils dominate (Arenosols, Umbrisols, Podzols, Cambisols and Gleysols). Loamy and sandy loam soils are found in the transition zones between marine and shore deposits. Monitoring of water and sediment discharge has been carried out since 1993 at the catchment outlet (northernmost point in the catchment). In 2008, continuous monitoring started at the outlet of the Gryteland sub-catchment (Fig. 1). The sub-catchment covers approximately $0.27 \mathrm{~km}^{2}$ and is dominated by relatively larger areas of sandy soils and forest in comparison with the main catchment (Kværnø and Stolte, 2012). Arable land in the catchment is mostly used for the production of cereals, i.e. winter and spring wheat, barley and rye. If not left under stubble over winter, soils are tine-cultivated, mouldboard-ploughed and/or harrowed in autumn. Additional surface roughness measurements for mouldboard-tilled surfaces were conducted in another catchment near Leirsund, Lillestrøm, $40 \mathrm{~km}$ north of Skuterud. This catchment was characterized by relatively flat slopes and higher soil clay content than in Skuterud.

\subsection{Data collection}

Soil roughness data were collected on four typical land units in the catchment in the period between March and June 2013. 


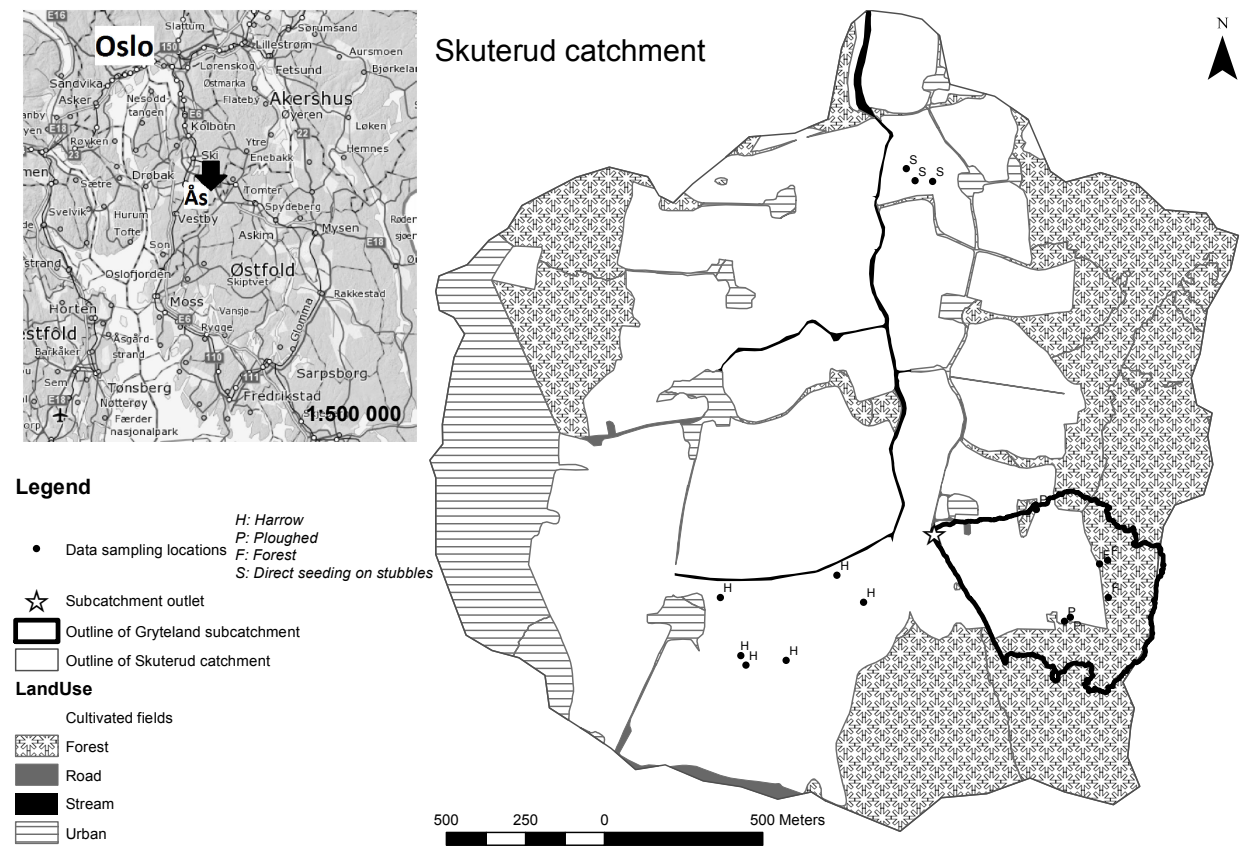

Figure 1. Outline and land use of the Skuterud catchment. The sub-catchment Gryteland is outlined in black. Data sampling locations are indicated. The inserted map in upper left corner indicates the location of the catchment. Land use map obtained from Bioforsk. Norway map obtained from http://www.skogoglandskap.no/kart/kilden.
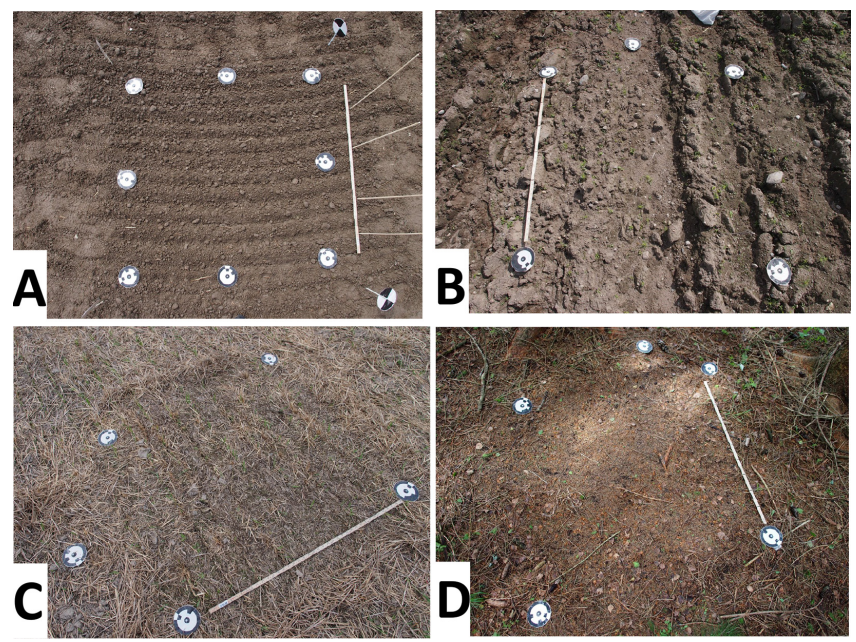

Figure 2. Pictures showing the setup of the measurement plot and the four different land use categories. The markers delineate an area of $1 \mathrm{~m}^{2}$. The patterns on the markers were used for the stereophoto technique. (a) Harrowed, (b) ploughed, (c) direct seeding on stubble and (d) forest.

Two tilled surfaces (harrowed and ploughed) and two untilled surfaces (direct seeding on stubble and forest) were analysed. In addition, three texture classes were initially defined to distinguish between land units, but preliminary data analysis showed no significant differences between the harrowed surfaces on two different texture classes. Therefore, no fur- ther differentiation in land units was made based on texture. On each land unit, at least three random locations were selected. As the fieldwork was conducted in late spring, when seedbed preparation had almost been completed throughout the catchment, there were hardly any mouldboard ploughed fields left, so part of the measurements on ploughed surface had to be done in the Leirsund catchment. At each location, a plot of $1 \mathrm{~m} \times 1 \mathrm{~m}$ was marked on which soil roughness measurements were taken (Fig. 2).

Soil roughness was measured using five different methods (Table 1; Fig. 3): roller chain, pinboard, stereophotos, TLS and the Xtion Pro. Four of these methods have been used before (Aguilar et al., 2009; Allmaras et al., 1966; Barneveld et al., 2013; Haubrock et al., 2009; Jester and Klik, 2005; Saleh, 1993), while the Xtion Pro is a novel technique (Mankoff and Russo, 2012). Two methods were contact methods (roller chain and pinboard) and three were noncontact, sensor methods (stereophotos, TLS and the Xtion Pro). For the sensor methods, each technique was applied on an area of $1 \mathrm{~m}^{2}$. For the pinboard method, two transects were recorded along and across the direction of cultivation on a $1 \mathrm{~m}^{2}$ area, while for the roller chain, three replicates along and across the direction of cultivation on the $1 \mathrm{~m}^{2}$ area were recorded. When roughness was isotropic (forest and direct seeding on stubble), between two and four replicates were taken on the plot.

The roller chain (Fig. 3a) used in this study had joints of $4 \mathrm{~mm}$, links of $6 \mathrm{~mm}$ and a total length of $1 \mathrm{~m}$. The chain was carefully laid out on the surface and the length covered 
Table 1. Land unit, number of plots, sample locations and point height measurements per method.

\begin{tabular}{llcl}
\hline $\begin{array}{l}\text { Land } \\
\text { unit }\end{array}$ & $\begin{array}{l}\text { Measurement } \\
\text { device }\end{array}$ & $\begin{array}{c}\text { Number of } \\
\text { sampling locations }\end{array}$ & $\begin{array}{l}\text { Total number } \\
\text { of readings }\end{array}$ \\
\hline Harrowed & $\begin{array}{l}\text { Roller chain } \\
\text { Harrowed }\end{array}$ & $8^{\mathrm{a}}$ & 40 transects \\
Harrowed & $\begin{array}{l}\text { Pinboard } \\
\text { Stereophotos }\end{array}$ & $8^{\mathrm{a}}$ & 20 transects $\times 50$ points $=1000$ points \\
Harrowed & Xtion Pro & $6^{\mathrm{b}}$ & 7 plots, average 38197 points \\
Harrowed & Laser scanner & 1 & 1 plots, average 76099 points \\
Ploughed & Roller chain & $6^{\mathrm{a}}$ & 38 transects 146 points \\
Ploughed & Pinboard & $6^{\mathrm{a}}$ & 18 transects $\times 50$ points $=850$ points \\
Ploughed & Stereophotos & $5^{\mathrm{b}}$ & 5 plots, average 36740 points \\
Ploughed & Xtion Pro & $3^{\mathrm{b}}$ & 3 plots, average 80027 points \\
Direct seeding on stubble & Roller chain & 3 & 18 transects \\
Direct seeding on stubble & Pinboard & 3 & 6 transects $\times 50$ points $=300$ points \\
Direct seeding on stubble & Stereophotos & 3 & 3 plots, average 89678 points \\
Direct seeding on stubble & Xtion Pro & 3 & 3 plots, average 67651 points \\
Forest & Roller chain & 3 & 18 transects \\
Forest & Pinboard & 3 & 6 transects $\times 50$ points $=300$ points \\
Forest & Stereophotos & 3 & 3 plots, average 87541 points \\
Forest & Xtion Pro & 3 & 3 plots, average 58794 points \\
Forest & Laser scanner & 1 & 1 plots, 2193589 points \\
\hline
\end{tabular}

a At one or two locations, two extra measurements were taken. Thus, for roller chain, the number of transects is not a multiple of 4 , as two extra measurements were included at two locations for harrowed and one location for ploughed, likewise for pinboard. ${ }^{\mathrm{b}}$ For harrowed and ploughed surfaces, some of the sensor measurements had to be discarded because of insufficient point coverage; therefore the number of locations is smaller than for the contact methods. ${ }^{\mathrm{c}}$ The number is relatively high compared to Xtion Pro; however, it is an average of three plots with respectively (rounding to nearest thousand) 41000,53000 and 168000 points. Thus, the number might be misleadingly high.

by the chain was measured with a ruler. The ratio between the distance over surface $(1 \mathrm{~m})$ over the Euclidean distance (measured by ruler) of the chain was used to calculate the chain roughness $(\mathrm{Cr})$ index, as a measure of the roughness. The $\mathrm{Cr}$ index is calculated using (Eq. 1) (Saleh, 1993)

$\mathrm{Cr}=\left(1-\frac{L 2}{L 1}\right) \times 100$,

where $L 1$ is the distance over surface [m] (here 1) and $L 2$ is the Euclidean distance [m]. The pinboard (Fig. 3b) used in this study was a frame of $1 \mathrm{~m}$ width with 50 metal pins, each $3 \mathrm{~mm}$ in diameter, with $18.5 \mathrm{~mm}$ spacing between the pins. While the pinboard was placed on the surface and a white screen was placed behind, a digital camera recorded an image from which the height of each individual pin later was estimated using the software program ImageJ (Rasband, 2013). The standard deviation of all recorded pin heights is a measure of the roughness.

Laser scanners have been used increasingly during the last 20 years in soil surface survey studies to obtain 3-D data of micro-topography (e.g. Aguilar et al., 2009; Barneveld et al., 2013; Haubrock et al., 2009; Takken, 2000). TLS height data were acquired using a Leica ScanStation2 (Fig. 3c). The scanner sends out pulsed laser beams and estimates distances by means of a time-of-flight principle (Leica-Geosystems AG, 2007). At the sensor head the pulsed beam is $4 \mathrm{~mm}$ in diameter, which increases to $6 \mathrm{~mm}$ at $50 \mathrm{~m}$ distance (Barneveld et al., 2013). The signals were processed using the licensed Cyclone software (Leica-Geosystems AG, 2014). Since a very limited area $\left(1 \mathrm{~m}^{2}\right)$ had to be covered, a single scan was enough to obtain a high accuracy. The angle between scanner and plot area was approximately $45^{\circ}$ and the scanner was placed approximately $2 \mathrm{~m}$ from the plot. Differences between laser beam footprints within the plot are assumed to be negligible since the plot only covers $1 \mathrm{~m}^{2}$.

Stereophoto images were constructed using a digital camera - an Olympus PEN E-P3 with a M. Zuiko Digital ED $12 \mathrm{~mm}$ f2.0 lens (Fig. 3d) - and the PhotoModeler software (Eos Systems Inc., 2011). The program links several images using the black-and-white markers (Fig. 2). In each plot, several images with slightly different view angles $\left(<45^{\circ}\right)$ were linked to establish the height differences. The method only works properly with angles up to $45^{\circ}$.

In 2010 a new depth-sensing technology was developed under the name Kinect (Kramer et al., 2012). It was originally intended for stationary indoor use in combination with a gaming console. The technology has proven to be quite accurate in depth estimates and has become of interest for geophysical research (Kramer et al., 2012; Mankoff and Russo, 2012). Subsequently, similar sensors started to be developed parallel to the development of the Kinect. In this study, the Xtion Pro was used (Fig. 3e). The Xtion Pro has an emitter that sends out an infrared pattern, which is reflected and recorded by the sensor on the device. This is used in a triangulation process to estimate distances (Khoshelham and 


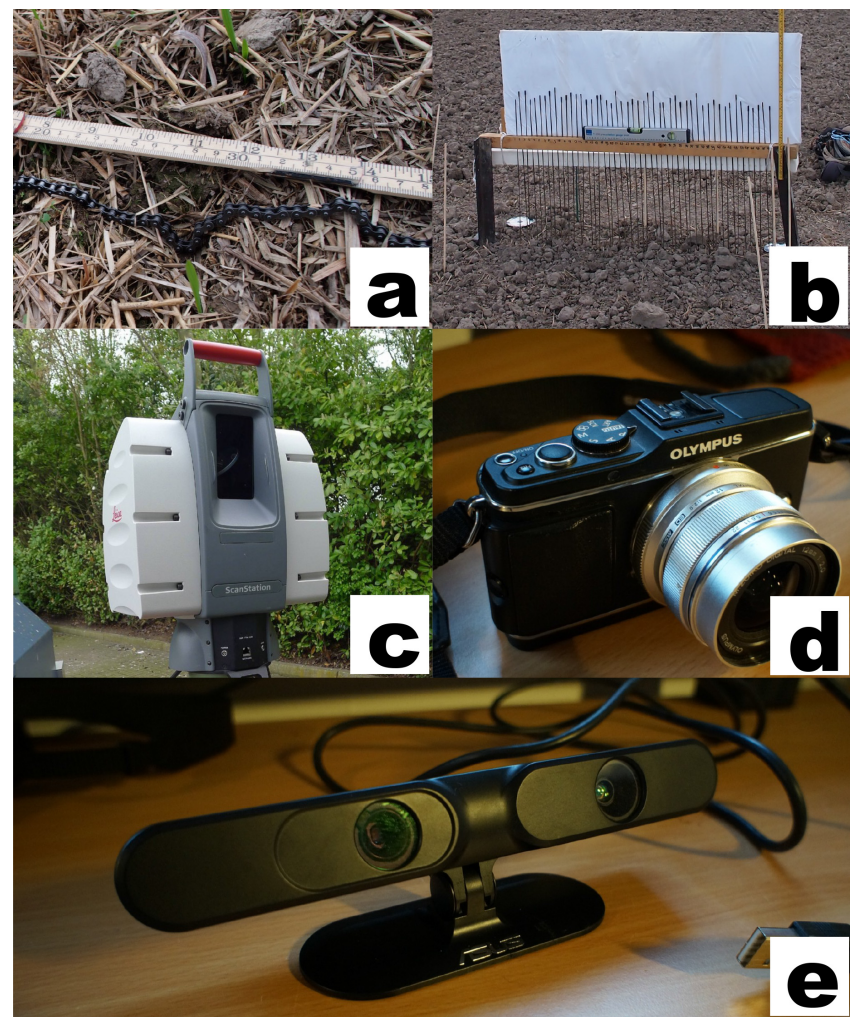

Figure 3. Five devices used for measuring soil surface roughness: (a) roller chain, (b) pinboard, (c) Leica terrestrial laser scanner, (d) the digital camera used for creating stereophotos, and (e) the Xtion Pro. Images (a) and (b) show contact methods, while (c), (d) and (e) show non-contact methods.

Elberink, 2012). The Xtion Pro was fixed to a wooden handle to be able to take recordings close enough to the soil surface with a $90^{\circ}$ angle to the plot. The sensor was connected to a laptop in order to communicate with the Skanect software (Tisserand and Burrus, 2013). The Xtion Pro recording had to be done without direct sunlight, as the natural light interferes with the infrared signal.

For all sensor methods, roughness was calculated as the standard deviation of the point heights in each point cloud.

An $\mathrm{H}$ flume was installed at the Gryteland sub-catchment outlet to measure overland flow. Water depth (logged at 10 min intervals) in the flume was measured using an ultrasonic sensor, and a conversion from depth to discharge was performed using a height-to-discharge relationship. Volume proportional samples from surface and drain discharge were taken during discharge episodes (Stolte and Kværnø, 2013).

\subsection{Data processing}

For each data sampling location, one roughness estimate per method was calculated. For the roller chain this was an average of four measurements and for the pinboard an average of two. Random roughness, calculated as a function of the height measurement, was used for the comparison. Thus, to be able to compare the roller chain with the other four methods, a conversion of the Cr index to the RR index was necessary. From the pinboard it is possible to estimate both the RR index and $\mathrm{Cr}$ index by summing up the Euclidean distance between consecutive pins. By plotting the two different indices from the same measurements in a scatter plot a regression between the two indices could be established. This was used to convert the $\mathrm{Cr}$ index to RR values (Jester and Klik, 2005). For the correlation, see Appendix A.

For each of the sensors a different software program was employed to transform the measurements to data files; however all data output was in $x y z$ coordinates (i.e. a point cloud) in an ASCII file format. To process data in an efficient way, a routine was developed in $\mathrm{R}$ (version 3.0.1, using $\mathrm{R}$ studio version 0.97 .511 ). This routine placed the coordinate system of each point cloud in the centre of the cloud; converted units to metres; cut out an area of $0.8 \mathrm{~m} \times 0.8 \mathrm{~m}$ to avoid side disturbance of the plot that would distort the roughness estimates; removed any slope effect by fitting a plane through the point cloud; and extracted height data by calculating the distance from each point to the plane. Finally the code removed outliers defined as heights larger than 3 times the standard deviation of the measurements. This was decided based on visual inspection of the point cloud where points floating above the soil surface were observed, supposedly artefacts created from sensor distortion. In contrast to other studies (Jester and Klik, 2005; Taconet and Ciarletti, 2007; Vaudour et al., 2014), the RR was calculated directly from the point cloud data points instead of by defining a grid. This was done to obtain the highest possible resolution and accuracy. If a grid was defined, the sub-grid micro-topography would have been averaged out because of the large minimum cell size required in order to obtain full point coverage of the plot.

\subsection{Comparison of measurement techniques}

RR results were compared between the different measuring techniques according to four aspects: accuracy, precision, data resolution and the price of the different devices. Accuracy, defined as how well a method reproduces the soil surface, was assessed using the TLS data as a reference, since TLS was the only device with documented, thorough accuracy tests in both indoor and outdoor environments (Aguilar et al., 2009; Barneveld et al., 2013; James and Quinton, 2014). Precision, defined as a measure of the data reproducibility of each method, was assessed using the standard deviation of multiple measurements on the same plot. Further, an ANOVA test was used to assess how well the methods agreed on an RR value for a specific land unit. Spatial resolution was defined as the number of points per square metre or per metre length (for the 2-D methods). Finally, the price of purchasing or using the different methods was compared. 


\subsection{Random roughness in the LISEM erosion model}

The Limburg Soil Erosion Model (LISEM) is an event-based spatially distributed and physically based model. It was originally developed to simulate the effect of local measures on soil loss in the province of Limburg in the Netherlands. The theoretical framework of the model has been described in detail in, for example, De Roo et al. (1996a) and Jetten (2002). In the model, RR is used to calculate surface storage in micro-depressions. In this study, the erosion model was run using the different average RR values resulting from each measurement method and the simulated hydrographs at the sub-catchment outlet were compared. By assessing how well the hydrographs of the rain event fitted the hydrograph obtained with the RR measured with TLS, the accuracy of each method relative to the TLS was evaluated.

\subsubsection{Surface storage in LISEM}

In LISEM, ponding on the surface is simulated using the concept of maximum depressional storage (MDS, cm). MDS is defined as the threshold value for a given area above which the surface micro-depressions will overflow. When this value is reached in any cell, each additional raindrop will directly result in overland runoff out of the cell. MDS is related to RR (Kamphorst et al., 2000) as follows (Eq. 2):

$\mathrm{MDS}=0.234 \mathrm{RR}+0.01 \mathrm{RR}^{2}+0.012 \mathrm{RR} \times S$,

where RR is random roughness [cm] and $S$ is terrain slope [\%]. As MDS is an expression for the maximum storage in any given cell, it is recognized that some runoff will occur before this threshold. This is modelled using the concept of start depressional storage (SDS, cm) (Eq. 3). When the SDS threshold is reached, some runoff occurs from a given cell. SDS is arbitrarily defined to be reached when $10 \%$ of a cell is ponded.

$\mathrm{SDS}=\frac{\ln (0.9)}{-\left(1.406 \times \mathrm{RR}^{-0.942}\right)}$

As long as the actual water height $h$ is smaller than SDS, no runoff occurs.

Runoff is a function of RR and slope, after interception and infiltration have been subtracted (Jetten, 2002). The fraction of the water height which runs off will increase when RR decreases, i.e. when the soil surface becomes less rough. The smoother the surface, the more water runs off.

\subsubsection{Simulated rain event and model settings}

A rainfall event from 4 September 2009, for which surface discharge was measured at the outlet of the Gryteland subcatchment, was used for the simulations. This event lasted approximately $12 \mathrm{~h}$, with a peak rain intensity of $18 \mathrm{~mm} \mathrm{~h}^{-1}$ and a total precipitation of $18.6 \mathrm{~mm}$. The LISEM model has been calibrated for the Gryteland sub-catchment using a rain event from August 2010 (Kværnø and Stolte, 2012). We used the same model settings for our simulations, including a spatial resolution of $10 \mathrm{~m}$ and model time step of $30 \mathrm{~s}$. The saturated hydraulic conductivity was re-calibrated, and was multiplied by a factor of 3 for the clay soils in the Gryteland catchment (versus a factor of 4.5 for the 2010 event) and Manning's $n$ value for arable land was set to 0.45 to match the measured hydrograph of 4 September 2009. The effect of the RR input values on the simulated outlet hydrograph was subsequently tested using the average values for each of the five measurement methods as input.

\section{Results and discussion}

\subsection{Comparison of methods}

Figure 4 shows the roughness values obtained with four different methods (the Xtion Pro, stereophotos, pinboard and roller chain) on the different land units (harrowed, ploughed, forest and direct seeding on stubble). The methods seem to be in better agreement on the harrowed and ploughed surfaces, concerning both mean and spread of data, whereas the two plots with vegetation show more varying RR values. The results of the ANOVA test indicated that there were significant differences between the RR values on plots with stubble. For each of the other surfaces, the methods were in agreement according to the ANOVA test. The precision of the methods varied between the methods, but it cannot be concluded that the precision of one method was higher than another, as the time constraint of the fieldwork only allowed for few replicates and a varying number of replicates for each land unit. The limited spread of the roller chain data on forest and stubble indicates that the surface was very homogeneous or that the roller chain was not able to capture differences present on these surfaces.

The vegetation residuals were not filtered out prior to the RR calculation even though RR is meant to express the soil surface roughness and not the general roughness. This might partly explain the disagreement between measurements on the forest and stubble plots, where vegetation residuals can distort the measurement. This would mainly be an issue for the non-contact methods and the chain, whereas the pinboard has the advantage that the pins can fit in between straws and still reproduce the height difference of the soil surface. For the stereophoto method, an explanation for the relatively low values and spread of RR data is that the plant residuals have too fine a structure to be reconstructed, resulting in an interpolated surface between some points, filtering out details. The Xtion Pro is also reported to have trouble reproducing surfaces with large height gradients, where the pattern recognition may fail locally (Mankoff and Russo, 2012). This means that plants with very thin structures might be skipped. However the RR values measured with the Xtion Pro on forest and stubble are significantly higher than those of the stereophoto method, which could indicate that the 

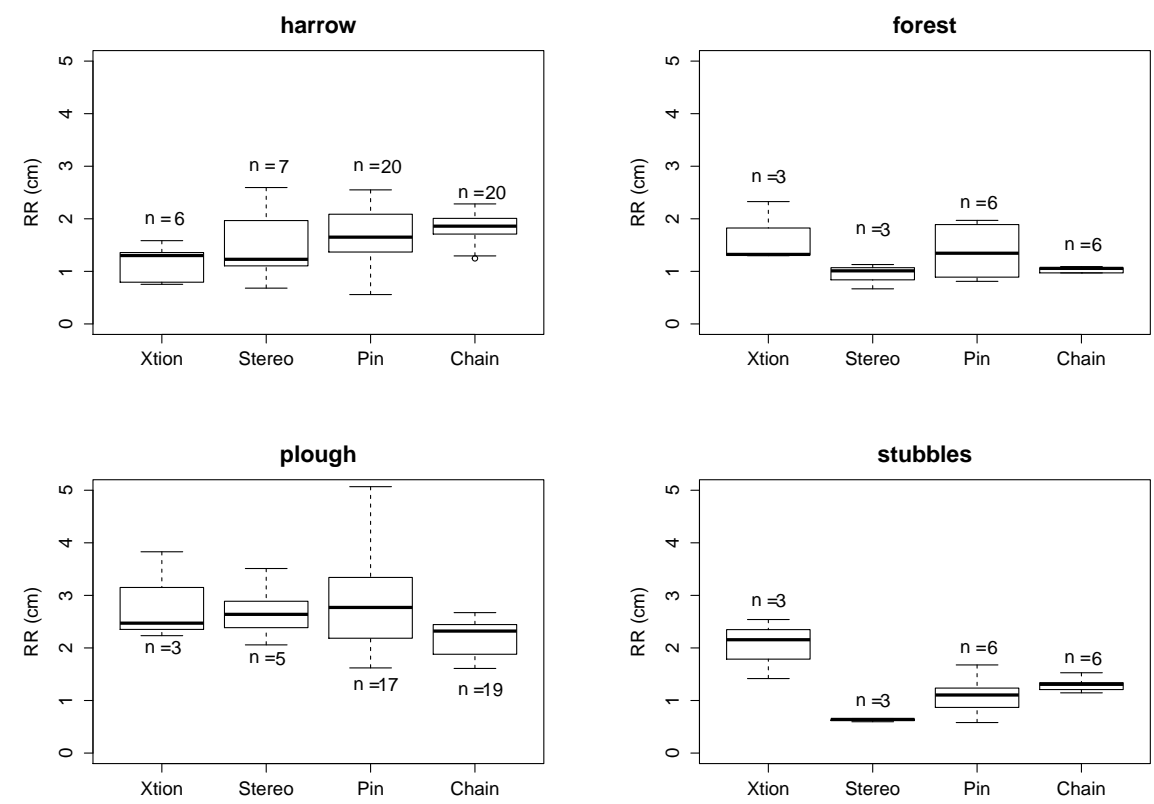

Figure 4. Box plot of RR values measured with four different methods on four different land units.

Xtion Pro manages to capture more height differences than the stereophoto. While this finding is based on the distribution of RR values and visual inspection of the point clouds (not shown), it would be beneficial to do more systematic point cloud comparisons in order to get a better understanding of the pros and cons of the Xtion Pro relative to the stereophoto technique. For the chain, the explanation for the relatively low values and spread of RR data could be that the size of the joints is too large to fit in between smaller soil aggregates, resulting in a smoother surface as reproduced by the roller chain than in reality. This means that the resolution of the chain method is restricting its applicability to surfaces that have relatively large soil aggregates, as also concluded by Jester and Klik (2005). Another restriction of the chain method is that it does not measure height differences but rather surface length differences (Skidmore, 1994).

Figure 5 shows the RR values for one plot on a harrowed field. Since roughness for each point cloud is calculated as the standard deviation of the full point cloud, only one number can be presented for the sensor methods. The numeric difference between the TLS, taken here as the most accurate method, and the other methods is smallest for the Xtion Pro $(-7 \%)$, intermediate for the stereophoto $(-16 \%)$ and pinboard $(+45 \%)$ and largest for the chain method $(+102 \%)$. Although it is not possible to base the argument on statistics, the results seems to indicate that the Xtion Pro is in better agreement with the TLS than the stereophoto and therefore more accurate. Likewise, the pinboard is in better agreement with the TLS than the chain. To further assess these first results in detail and to be able to base them on statistics, more replicates are needed.

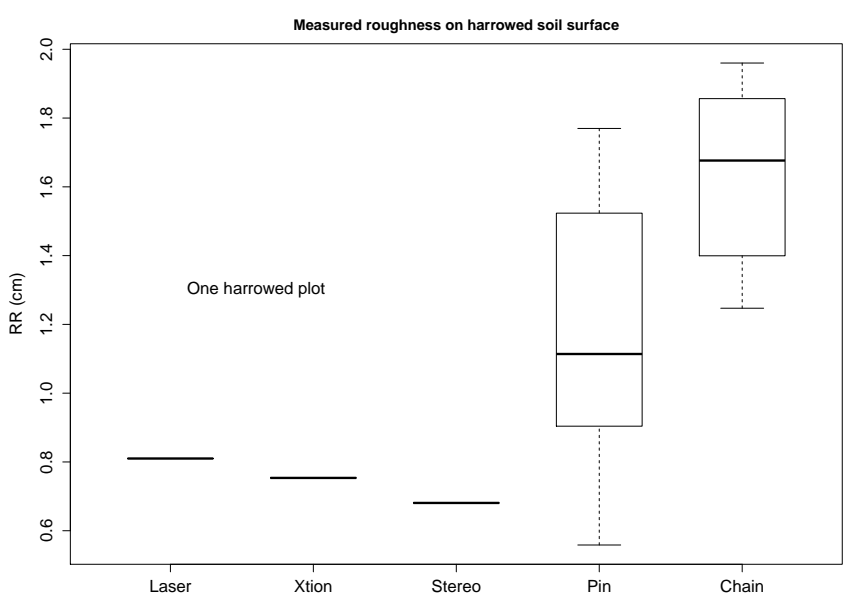

Figure 5. Random roughness (RR) values for one harrowed plot based on five different measurement methods.

Each of the RR values acquired by non-contact methods is the standard deviation of a minimum of 57000 height point measurements on $1 \mathrm{~m}^{2}$, and thus it can be argued that this is a representative number for this land unit. While most sensors are reported with accuracy estimates, the actual accuracy of the field data are affected by environmental factors, which ideally should be known before using the method (Barneveld et al., 2013). For future studies it will be useful to perform thorough accuracy tests under field conditions, for instance with objects of known dimensions placed in the field. This will be especially useful in the case of the Xtion Pro in order to fully assess the potential of this sensor in earth science studies. 


\subsection{Data resolution}

For the roller chain, the size of the joints represents the degree of detail the chain is able to measure; however the resolution is not easy to evaluate. For the pinboard, the resolution was 100 points per metre or 10000 points per square metre. In contrast, each of the sensor methods had at least 57000 points per square metre. While the TLS had a resolution of 2 million points per square metre, the Xtion Pro and stereophotos had fluctuating resolutions based on the physical properties of the soil surface and the environmental conditions. For example, on a ploughed plot, the shading caused by steep furrows caused gaps in the stereophoto data. The very large local gradients on the ploughed surfaces also caused trouble for the Xtion Pro in some cases. The software program is made for smooth surfaces, and thus it seems that the software program smoothed out deeper cavities in the surface. From the software documentation (Tisserand and Burrus, 2013) it was not possible to obtain further information regarding this issue. It should be noted that TLS measurements represent an oversampling of the plot; overlapping points will not increase the accuracy when the repulsed laser beams have a footprint of $4 \mathrm{~mm}$. However, if the point clouds were converted to grids, the confidence in the single cell height values would be increased.

It should be kept in mind that the various sensors use different techniques for estimating distance and that different algorithms are applied in the data processing. Although the software programs sometimes report accuracy estimates, it was unknown which approaches and algorithms were used when the software programs were applied to process the measurements of both the TLS (Leica-Geosystems AG, 2014) and the Xtion Pro (Tisserand and Burrus, 2013). Although these routines are improving the quality of the recorded data, it is not guaranteed that the data from different devices are treated consistently, which could be problematic when the data are compared. The quality of the data produced by the sensors will improve when the algorithms are better documented and is an issue that requires further attention.

\subsection{Price of devices}

Table 2 provides an overview of the approximate costs related to the various methods. The contact methods are significantly cheaper than the sensor methods. Of the sensor methods, the Xtion Pro is by far the cheapest. It should, however, be kept in mind that a digital camera can be used for many other purposes, and as such the comparison is only indicative. In addition, the Xtion Pro needs a computer with a highresolution graphics card to analyse the data. The price of the computer is not included in the comparison. Likewise, it is possible that the TLS can be rented rather than purchased, in which case it becomes cheaper than indicated here.

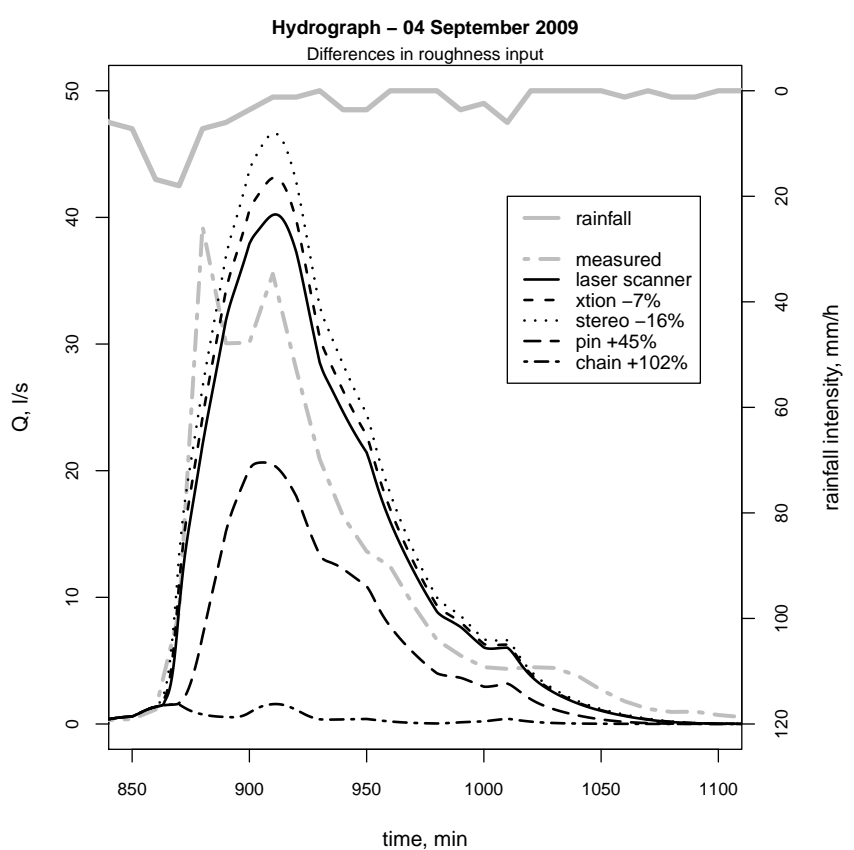

Figure 6. Model output as a function of mean RR values per method for harrowed fields.

\subsection{Roughness values as input to an erosion model}

The hydrograph output from the erosion model, based on model runs with RR input values from the different methods, is shown in Fig. 6. The RR values obtained with the Xtion Pro and stereophotos were lower than those obtained with the TLS (Fig. 5) and produced hydrographs with a slightly higher peak discharge (43 and $47 \mathrm{~L} \mathrm{~s}^{-1}$ for Xtion Pro and stereophoto, respectively, vs. $40 \mathrm{~L} \mathrm{~s}^{-1}$ for TLS). Similarly, the pinboard and chain method produced higher roughness values, which resulted in lower peak discharges. This is most noticeable for the chain method, which simulated a peak discharge of only $1.5 \mathrm{~L} \mathrm{~s}^{-1}$. This was less than half the amount of the measured discharge and the discharge simulated with the calibrated model using the TLS RR data.

The model results can be explained by looking at Eqs. (2) and (3). In Eq. (2), a higher RR value results in a higher MDS, which reduces the amount of surface runoff from each cell. A smaller RR value instead reduces MDS and thereby increases the amount of surface runoff. In Eq. (3), a higher RR value reduces SDS and thereby increases the amount of water which can be stored in each cell and vice versa.

These results clearly show the importance of the RR input values on the simulated hydrograph and the effect that different measurement techniques have. To ensure consistency in a field campaign, it is crucial that the same device is used. The model sensitivity to RR is determining how accurate the data need to be - this means that a standardized method and number of replicates should be stated in the model user manual 
Table 2. Approximate prices related to roughness measurement devices. All prices are in euros. Note that the prices might be subject to change depending on country, might be lower due to temporary offers, and might fluctuate subsequent to the time in which this study was done.

\begin{tabular}{lrlr}
\hline Technique & $\begin{array}{r}\text { Price of } \\
\text { device }\end{array}$ & Software & Price of software \\
\hline Roller chain & 74 & - & 0 \\
Pinboard (home-made) & 30 & freeware (ImageJ) & 0 \\
Stereophotogrammetry & 1000 & PhotoModeler & 2145 \\
Leica terrestrial laser scanner & 60000 & Cyclone (the price of device includes the software) & - \\
Xtion Pro & 100 & Skanect & 100 \\
\hline
\end{tabular}

and different measurement methods within the same study (area) should be avoided.

It should be taken into account that this result is based on a small homogeneous catchment. The effect in larger areas with more heterogonous RR values should be assessed as well.

\section{Conclusions}

This study is, to our knowledge, the first that directly compared five different techniques to measure random roughness, one of which is the new Xtion Pro method, which originates in the gaming industry and is applied here to measure roughness in an earth sciences context. It can be concluded that, for measuring soil roughness, the choice of method matters, as proven by the statistical tests and the differences in model output in this study. Which method is the best choice depends on required accuracy and resolution, mobility in the field and available budget. In general, the resolution of the contact methods (roller chain and pinboard) seems to restrict their applicability, not to mention how time-consuming and impractical they are in the field. In contrast, the Xtion Pro has proven to be a useful, cheap and accurate sensor and a promising alternative to TLS and stereophotos, although more research is needed regarding accuracy and software.

The TLS and stereophoto technique each have their own advantages. The digital camera gives the user most mobility but requires expert software to process. The TLS ensures highest accuracy and resolution in outdoor environments but is not practical to use in extensive field measurement campaigns because of all the required equipment.
The choice of roughness measurement device is important when the data are used as input for an erosion model, as shown for the LISEM model in this study. With respect to the inconsistencies that can be expected between roughness measurement devices, it would be useful to attach information regarding the measuring device and number of necessary replicates to the model guidelines.

The sensitivity of LISEM to RR is determined by equations based on empirical relations found during field trials. Thus, the method and device should match the ones used in this empirical study (Kamphorst et al., 2000) so as to be in line with the values that were used to establish the equation, rather than getting the highest possible accuracy or resolution. Interestingly, in Kamphorst et al. (2000), roughness was determined with a pinboard and a laser scanner, with all roughness values averaged together.

With the sensor methods, a representative 3-D image of the microtopography could be created which potentially incorporates more information regarding surface roughness than is included in the RR index. Thus, while the high-resolution sensors are becoming cheaper and more mobile, it is worth considering whether overland flow should be estimated using other indices or methods than the RR index and the maximum storage capacity concept. 


\section{Appendix A}

Figure A1 shows a scatter plot of the $\mathrm{Cr}$ index calculated based on measurements from the roller chain against the $\mathrm{Cr}$ index calculated based on the Euclidean distances between consecutive pins from the pinboard. A linear regression can be established with a satisfying $R^{2}$ value. It can be seen that the $R^{2}$ value increases when the regression is made based on mean values per land use.

Figure A2 shows the non-linear regression fitted to the scatter plot of the $\mathrm{Cr}$ index from the chain against the RR measured with the pinboard. Three outliers were excluded from the regression to create a better fit.

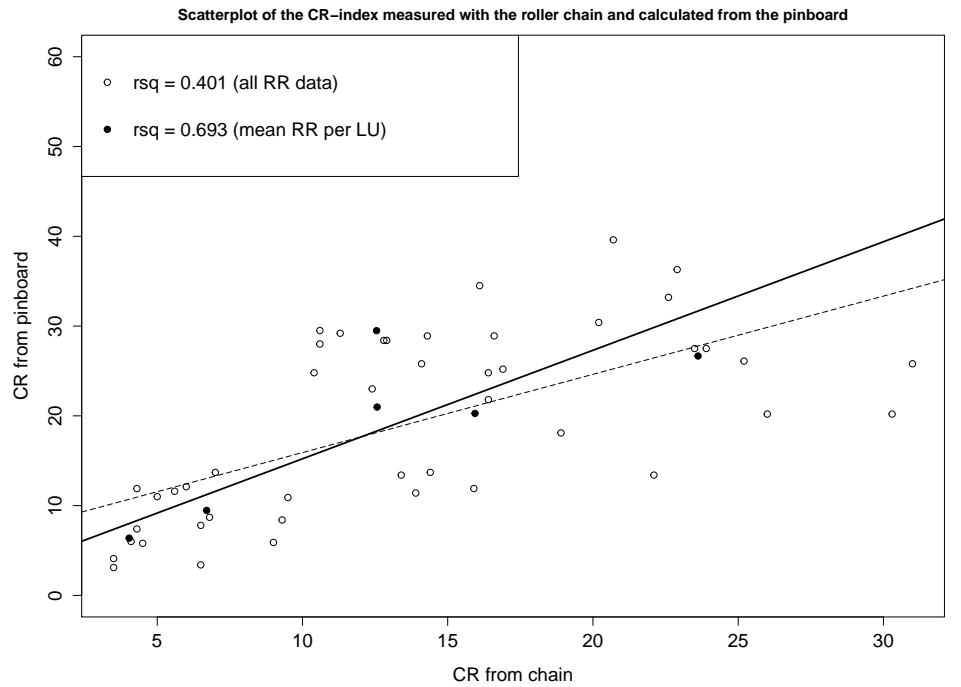

Figure A1. Linear regression between the $\mathrm{Cr}$ index measured with the roller chain and the pinboard. The dashed line shows the regression using all the RR data, whereas the solid line shows the regression using one mean RR value per land use. Using the mean RR values yields a higher $R^{2}$ value than using all the RR data, as can be seen in the box (upper left corner).

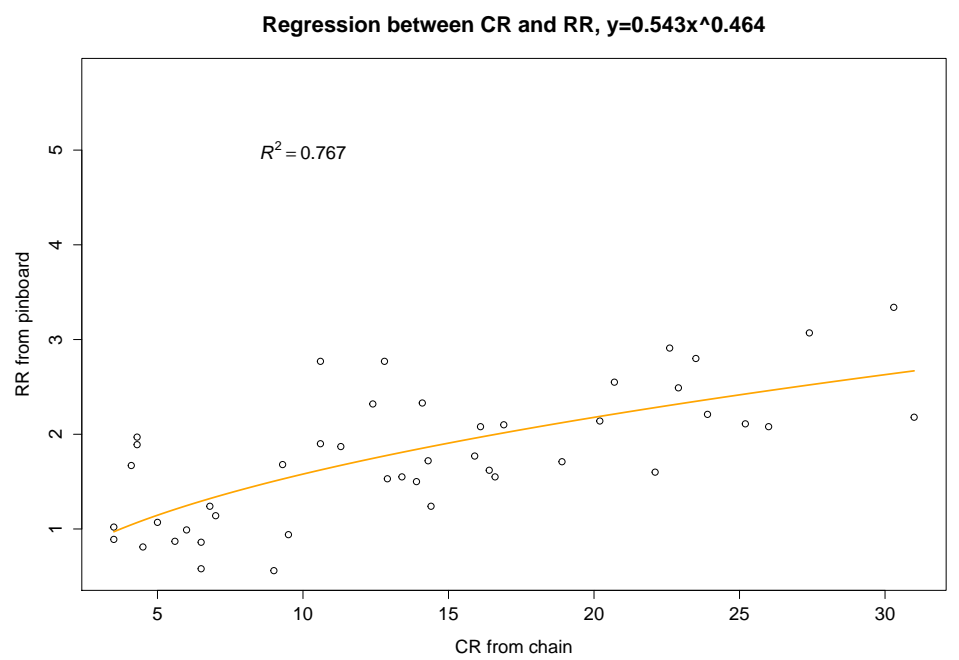

Figure A2. Non-linear regression used to convert the $\mathrm{Cr}$ index to $\mathrm{RR}$ values. 
Acknowledgements. The authors gratefully acknowledge the contribution of Christophe Moni (development of point cloud processing routine in $\mathrm{R}$ ) at Bioforsk. The research was financed through the SIS-Catchy project of Bioforsk.

Edited by: M. Seeger

\section{References}

Aguilar, M. A., Aguilar, F. J., and Negreiros, J.: Off-the-shelf laser scanning and close-range digital photogrammetry for measuring agricultural soils microrelief, Biosyst. Eng., 103, 504-517, 2009.

Allmaras, R. R., Burwell, R. E., Larson, W. E. and Holt, R. F.: Total porosity and random roughness of the interrow zone as influenced by tillage, available at: http://www.ars.usda.gov/ sp2UserFiles/Place/36221500/cswq-t1914-allmaras.pdf, (last access: 9 November 2014), 1966.

Amoah, J. K. O., Amatya, D. M., and Nnaji, S.: Quantifying watershed surface depression storage: determination and application in a hydrologic model, Hydrol. Process., 27, 2401-2413, doi:10.1002/hyp.9364, 2013.

ASUS: Xtion Pro, available at: http://www.asus.com/Multimedia/ Xtion_PRO/ (last access: 1 October 2014), 2013.

Barneveld, R. J., Seeger, M., and Maalen-Johansen, I.: Assessment of terrestrial laser scanning technology for obtaining highresolution DEMs of soils, Earth Surf. Process. Landf., 38, 90-94, doi:10.1002/esp.3344, 2013.

Brouwer, T.: Low budget ranging for forest management?: a Microsoft Kinect study, Wageningen University, Wageningen, Netherlands, 68 pp., available at: http://edepot.wur.n1/309838 (last access: 13 April 2015), 2013.

Cremers, N. H. D. T., Van Dijk, P. M., De Roo, A. P. J., and Verzandvoort, M. A.: Spatial and temporal variability of soil surface roughness and the application in hydrological and soil erosion modelling, Hydrol. Process., 10, 1035-1047, 1996.

De Roo, A. P. J. D. E., Wesseling, C. G., and Ritsema, C. J.: LISEM?: A single-event physically based hydrological and soil erosion model for drainage basins. I: Theory, input and output, Hydrol. Process., 10, 1107-1117, 1996a.

De Roo, A. P. J., Offermans, R. J. E., and Cremers, N. H. D. T.: LISEM: A single-event, physically based hydrological and soil erosion model for drainage basins. II: Sensitivity analysis, validation and application, Hydrol. Process., 10, 11191126, doi:10.1002/(sici)1099-1085(199608)10:8<1119::aidhyp416>3.0.co;2-v, $1996 \mathrm{~b}$.

De Vente, J., Poesen, J., Verstraeten, G., Govers, G., Vanmaercke, M., Van Rompaey, A., Arabkhedri, M., and Boix-Fayos, C.: Predicting soil erosion and sediment yield at regional scales: Where do we stand?, Earth-Sci. Rev., 127, 16-29, doi:10.1016/j.earscirev.2013.08.014, 2013.

Doren, D. R. and Van Linden, D. M.: Parameters for Characterizing Tillage-induced Soil Surface Roughness, Soil Sci. Soc. Am. J., 50, 1-6, 1986.

Eos systems Inc.: Photomodeler Scanner, available at: http://www. photomodeler.com/index.html, (last access: 9 November 2014), 2011.

Esteves, M., Faucher, X., Galle, S., and Vauclin, M.: Overland flow and infiltration modelling for small plots during unsteady rain: numerical results versus observed values, J. Hydrol., 228, 265282, 2000.

Fiedler, F. R. and Ramirez, J. A.: A numerical method for simulating discontinuous shalloe flow over and infiltrating surface, Int. J. Numer. Methods Fluid., 32, 219-240, 2000.

García Moreno, R., Díaz Álvarez, M. C., Tarquis, A. M., Paz González, A., and Saa Requejo, A.: Shadow analysis of soil surface roughness compared to the chain set method and direct measurement of micro-relief, Biogeosciences, 7, 2477-2487, doi:10.5194/bg-7-2477-2010, 2010.

Hammerle, M., Hofle, B., Fuchs, J., Schroder-Ritzrau, A., Vollweiler, N., and Frank, N.: Comparison of Kinect and Terrestrial LiDAR Capturing Natural Karst Cave 3-D Objects, Geosci. Remote Sens. Lett. IEEE, 11(11), 1896-1900, doi:10.1109/LGRS.2014.2313599, 2014.

Haubrock, S.-N., Kuhnert, M., Chabrillat, S., Güntner, A. and Kaufmann, H.: Spatiotemporal variations of soil surface roughness from in-situ laser scanning, Catena, 79, 128-139, doi:10.1016/j.catena.2009.06.005, 2009.

James, M. R. and Quinton, J. N.: Ultra-rapid topographic surveying for complex environments: the hand-held mobile laser scanner (HMLS), Earth Surf. Process. Landf., 39, 138-142, doi:10.1002/esp.3489, 2014.

Jester, W. and Klik, A.: Soil surface roughness measurement-methods, applicability, and surface representation, Catena, 64, 174-192, doi:10.1016/j.catena.2005.08.005, 2005.

Jetten, V.: LISEM - Limburg Soil Erosion Model - User manual, available at: http://www.itc.nl/lisem/download/lisemmanualv2x. pdf (last access: 9 November 2014), 2002.

Kamphorst, E. C., Jetten, V., Guérif, J., Pitkänen, J., Iversen, B. V., Douglas, J. T., and Paz, A.: Predicting Depressional Storage from Soil Surface Roughness, Soil Sci. Soc. Am. J., 64, 1749-1758, 2000.

Khoshelham, K. and Elberink, S. O.: Accuracy and resolution of Kinect depth data for indoor mapping applications., Sensors, 12, 1437-1454, doi:10.3390/s120201437, 2012.

Kramer, J., Burrus, N., Echtler, F., Herrera, D., and Parker, M.: Hacking the Kinect, 1st Edn., Apress, 268 pages, 2012.

Kværn $\varnothing$, S. H.: Variability and incertainty in sol physical properties: Effects of data source on functional criteria, Bioforsk Soil and Environment, Norwegian University of Life Sciences, Ås, Norway, 45 pp., 2011.

Kværn $\varnothing$, S. H. and Stolte, J.: Effects of soil physical data sources on discharge and soil loss simulated by the LISEM model, Catena, 97, 137-149, 2012.

Lehrsch, G. A., Whisler, F. D., and Römkens, M. J. M.: Selection of a Parameter Describing Soil Surface Roughness, Soil Sci. Soc. Am. J., 52, 1439-1445, doi:10.2136/sssaj1988.03615995005200050044x, 1988.

Leica-Geosystems AG: Leica ScanStation 2 Product Specifications, available at: http://hds.leica-geosystems.com/downloads123/ hds/hds/ScanStation/brochures-datasheet/Leica_ScanStation2_ datasheet_us.pdf (last access: 8 September 2013), 2007.

Leica-Geosystems AG: Leica Cyclone 9.0, available at: http://hds. leica-geosystems.com/en/Leica-Cyclone_6515.htm (last access: 1 October 2014), 2014.

Mankoff, K. D. and Russo, T. A.: The Kinect: A low-cost, highresolution, short-range 3D camera, Earth Surf. Process. Landf., 38, 926-936, doi:10.1002/esp.3332, 2012. 
Rasband, W.: ImageJ - documentation, available at: http://rsbweb. nih.gov/ij/docs/index.html (last access: 2 September 2013), 2013.

Saleh, A.: Soil roughness measurement?: Chain method, J. Soil Water Conserv., 48, 527-529, 1993.

Sheikh, V., van Loon, E., Hessel, R., and Jetten, V.: Sensitivity of LISEM predicted catchment discharge to initial soil moisture content of soil profile, J. Hydrol., 393, 174-185, 2010.

Skidmore, E. L.: Comment on Chain Method for Measuring Soil Roughness, Soil Sci. Soc. Am. J., 61, 1 p., 1994.

Stolte, J. and Kværnø, S. H.: Snowmelt and runoff in two small field-scale catchments, in: Agriculture and Environment - Long term Monitoring in Norway, edited by: Bechmann, M. and Deelstra, J., Akademika Publishing, Trondheim, Norway, 163-179, 2013.

Taconet, O. and Ciarletti, V.: Estimating soil roughness indices on a ridge-and-furrow surface using stereo photogrammetry, Soil Till. Res., 93, 64-76, doi:10.1016/j.still.2006.03.018, 2007.
Takken, I.: Effects of roughness on overland flow and erosion, Katholieke Universiteit Leuven, Leuven, Belgium, 218 pp., 2000.

Takken, I., Beuselinck, L., Nachtergaele, J., Govers, G., Poesen, J., and Degraer, G.: Spatial evaluation of a physically-based distributed erosion model (LISEM), Catena, 37, 431-447, 1999.

Tisserand, N. and Burrus, N.: Skanect support, available at: http: //skanect.occipital.com/support/ (last access: 5 December 2013), 2013.

Tortini, R., Bonali, F. L., Corazzato, C., Carn, S. A., and Tibaldi, A.: An innovative application of the Kinect in Earth sciences: quantifying deformation in analogue modelling of volcanoes, Terra Nov., 26, 273-281, doi:10.1111/ter.12096, 2014.

Vaudour, E., Baghdadi, N., and Gilliot, J. M.: Mapping tillage operations over a peri-urban region using combined SPOT4 and ASAR/ENVISAT images, Int. J. Appl. Earth Obs. Geoinf., 28, 43-59, doi:10.1016/j.jag.2013.11.005, 2014.

Zobeck, T. M. and Onstad, C. A.: Tillage and rainfall effects on random roughness: A review, Soil Till. Res., 9, 1-20, 1987. 